\title{
THREE-DIMENSIONAL CREEP ANALYSES OF THE LEANING TOWER OF PISA
}

\author{
J. BAi ${ }^{\text {i) }}$ N. MORGENSTERN ${ }^{\text {ii) }}$ and D. CHAN ${ }^{\text {iii) }}$
}

\begin{abstract}
Three-dimensional creep analyses are carried out to investigate the significance of soil creep effects on the tilting history of the Pisa Tower. Sensitivity analyses of model parameters are also conducted. Results show that three-dimensional creep analysis, although very time-consuming, is necessary in order to obtain more realistic numerical results. Creep effects have been found to account for 1.5 degrees out of the total 5.5 degrees inclination. Creep causes stress states in the clay layers to move away from the critical state line. It was also found that the deformation behaviour of the soil is not sensitive to any specific parameters. This helps to clarify that the total tilting angle of 5.5 degrees cannot be achieved by creeping of the soil. There must be other reasons that also contribute to the tilting of the tower, which cannot be considered by the constitutive model. Nevertheless, the current study could calculate the tilting history of the tower within reasonable accuracy during its construction period and illustrate more or less, the same trend as observed through the last four centuries. The model could also match the observed maximum settlement on top of the upper clay layers extremely well. Therefore, this study provides considerable insight into the deformation history of the soil and the stresses that are likely to exist in the soil.
\end{abstract}

Key words: creep, finite element, Pisa soil, Pisa Tower, settlement, three-dimensional analyses, tilting (IGC: E2)

\section{NTRODUCTION}

It is well known for the past seven centuries that the world famous Leaning Tower of Pisa has been tilting slowly towards its south side, with growing risk of a sudden collapse. In order to save this famous monument, many ideas and projects have been submitted from time to time from all over the world. Some of them are technically based, but the majority is the product of pure imagination (Lizzi, 1990). Before these ideas and projects can be implemented, the reason that causes the continuous movement with time under a constant load needs to be fully understood. One of the possible explanations is that the foundation soil is undergoing continuous creep deformation. Results from the creep tests on the Pisa clay conducted by both Bishop and Lovenbury (1969) and Mitchell and Soga (1995) have shown that creep deformation is important in the Pisa soil. Previous numerical investigations conducted by Burland and Potts (1995) and Mitchell and Soga (1995) also emphasised that in order to fully simulate the deformation behaviour of the Pisa soil, creep analysis was necessary. Results from two-dimensional creep analyses conducted by Bai (1998) highlighted the time-dependent deformation behaviour of Pisa clay, but the calculated final tilting angle was smaller than the actual 5.5 degrees. Clarification is necessary to determine whether the difference in the final tilting angle is due to the limitation of the two-dimensional analysis itself or some other reasons. On the other hand, two-dimensional analysis needs two correction factors to convert the real three-dimensional footing and loads into a strip footing and a load with unit length. It is of interest to find out whether careful selection of the values for these two correction factors in the two-dimensional analysis could provide a good representation of the stresses and deformations for the real three-dimensional problem. Threedimensional creep analyses with and without the tower structure are necessary in order to obtain answers for these questions.

The study described herein represents an attempt to carry out creep analysis of the Pisa soil. A time-dependent plastic model named the double-yield surface Camclay plasticity (DYSCP) model developed by Borja and Kavazanjian (1985) and Hsieh et al. (1990) was adopted. This model has been used efficiently in the time-dependent analysis of some field cases under two-dimensional conditions (Borja et al., 1990; Brandes et al., 1994; Morsy et al., 1995). In this study, this model was extended to handle three-dimensional cases through a finite element program PISA ${ }^{\circledR}$ (2007). As the first application of the DYSCP model in three-dimensional conditions, visco-plastic analyses of the Pisa soil with and without the

i) Senior Civil Engineer, Engineering Department, The Metropolitian Water Reclamation of Greater Chicago, Chicago, USA.

i) Professor Emeritus, Department of Civil \& Environmental Engineering, University of Alberta, Canada.

iii) Professor, ditto (dave.chan@ualberta.ca).

The manuscript for this paper was received for review on May 17, 2006; approved on February 5, 2008.

Written discussions on this paper should be submitted before November 1, 2008 to the Japanese Geotechnical Society, 4-38-2, Sengoku, Bunkyo-ku, Tokyo 112-0011, Japan. Upon request the closing date may be extended one month. 
tower were conducted. Through the ensuing work, creep effects on the deformation behaviour and stress response of the Pisa soil were investigated in detail. The capability of the numerical model in predicting the stress-straintime behaviour under a three-dimensional field case was illustrated. A better understanding of the deformation mechanism of the Pisa Tower was obtained.

\section{DESCRIPTION OF THE CONSTITUTIVE MODEL}

Creep phenomenon in soils has been studied for over five decades. Various creep models have been developed, but unfortunately most of them still remain at the research level. The double-yield surface Cam-clay plasticity (DYSCP) model developed by Borja and Kavazanjian (1985) and Hsieh et al. (1990) has been adopted in this study due to its simplicity and successful application in some field cases (Borja et al., 1990; Brandes et al., 1994; Morsy et al., 1995).

In the DYSCP model, the strain-rate tensor is decomposed into immediate or time-independent portions (elastic $\underline{\dot{\varepsilon}}^{\mathrm{e}}$, and plastic $\underline{\dot{\varepsilon}}_{\mathrm{F}}^{\mathrm{p}}$ and $\underline{\dot{\varepsilon}}_{\mathrm{G}}^{\mathrm{p}}$ ) and a delayed or time-dependent portion (creep $\dot{\dot{\varepsilon}}^{\mathrm{t}}$ ).

$$
\underline{\dot{\varepsilon}}=\underline{\dot{\varepsilon}}^{\mathrm{e}}+\dot{\dot{\varepsilon}}_{\mathrm{F}}^{\mathrm{p}}+\underline{\dot{\varepsilon}}_{\mathrm{G}}^{\mathrm{p}}+\underline{\dot{\varepsilon}}^{\mathrm{t}}
$$

where superscripts $e$ and $p$ denote the immediate elastic and plastic parts, respectively; superscript $t$ denotes the delayed or creep part; and subscripts $F$ and $G$ denote the Modified Cam-clay model and the Von-Mises yield surfaces, respectively. The creep strain rate tensor $\dot{\varepsilon}^{t}$ can be further decomposed into distinct, but interdependent volumetric and deviatoric parts

$$
\underline{\dot{\varepsilon}}^{\mathrm{t}}=\underline{\dot{\varepsilon}}_{\mathrm{v}}^{\mathrm{t}}+\underline{\dot{\varepsilon}}_{\mathrm{d}}^{\mathrm{t}}
$$

where subscripts $v$ and $d$ denote volumetric and deviatoric creep components, respectively. These two components can be evaluated through Taylor's (1948) secondary creep law and Singh and Mitchell's (1968) creep equation

$$
\begin{aligned}
& \dot{\varepsilon}_{\mathrm{v}}^{\mathrm{t}}=\frac{\psi}{(1+e) t_{\mathrm{v}}} \\
& \dot{\varepsilon}_{\mathrm{d}}^{\mathrm{t}}=A e^{\bar{\alpha} \overline{\mathrm{D}}\left[\frac{\left(t_{\mathrm{d}}\right)_{\mathrm{i}}}{t_{\mathrm{d}}}\right]^{\mathrm{m}}}
\end{aligned}
$$

where $\psi$ denotes the secondary compression coefficient, in natural logarithm scale; $e$ denotes the void ratio; $t_{\mathrm{v}}$ denotes the volumetric age, relative to the initial reference time $\left(t_{\mathrm{v}}\right)_{\mathrm{i}}$ (usually set to unity), it is a measure of void ratio reduction due to creep; $A, \bar{\alpha}$, and $m$ denote the Singh and Mitchell creep parameters; $\left(t_{\mathrm{d}}\right)_{\mathrm{i}}$ denotes the instant deviatoric time, usually set to unity; $t_{\mathrm{d}}$ denotes the deviatoric age relative to $\left(t_{\mathrm{d}}\right)_{\mathrm{i}}$, it is a measure of the shear strain due to overconsolidation; and $\bar{D}$ denotes the deviatoric stress level,

$$
\bar{D}=\frac{\left(\sigma_{1}-\sigma_{3}\right)}{\left(\sigma_{1}-\sigma_{3}\right)_{\mathrm{ult}}} .
$$

The double yield criteria are used to evaluate both the time-independent and time-dependent strain compo- nents. A detailed derivation of this model can be found in Hsieh et al. (1990), Morsy (1994), and Bai (1998).

\section{NUMERICAL STABILITY CRITERIA}

In visco-plastic analysis with a variable time scheme, oscillating results can be obtained if time steps exceed a certain magnitude; which indicates the instability of the process. In consideration of accuracy, two empirical rules have been proposed (Zienkiewicz and Cormeau, 1974; Cormeau, 1975). The first rule relates the time step magnitude to the anticipated changes of visco-plastic strain. A convenient scalar measurement of the visco-plastic strain is obtained by the second strain invariant defined as

$$
\bar{\varepsilon}=\sqrt{\frac{2}{3} \varepsilon_{\mathrm{ij}} \varepsilon_{\mathrm{ij}}}=\sqrt{\frac{2}{3}\left(\varepsilon_{11}^{2}+\varepsilon_{22}^{2}+\varepsilon_{33}^{2}+2\left(\varepsilon_{12}^{2}+\varepsilon_{23}^{2}+\varepsilon_{31}^{2}\right)\right.}
$$

where $\varepsilon_{\mathrm{ij}}$ represents the strain components, $i, j=1,2,3$. The maximum increment of this scalar visco-plastic strain should be limited to a certain fraction of the total accumulated strain at all integrating points, as follows

$$
\Delta t^{\mathrm{n}}=\tau\left[\frac{\bar{\varepsilon}^{\mathrm{n}}}{\dot{\bar{\varepsilon}}^{\mathrm{n}}}\right]_{\min }^{1 / 2}
$$

where $\Delta t^{\mathrm{n}}$ is the time increment at step number $n$; $\tau$ is the time-increment parameter, its value must be specified by the user. For an explicit scheme, $\tau$ is in the range of 0.01 to $0.15 ; \bar{\varepsilon}^{\mathrm{n}}$ is the second total strain invariant at step $n ; \dot{\bar{\varepsilon}}^{\mathrm{n}}$ is the second strain rate invariant at step $n$; and ' $m i n$ ' is the minimum value of $\Delta t^{\mathrm{n}}$ (time step), which is taken over all the integration points.

The second rule is imposed to relate the change of time step between successive intervals.

$$
\Delta t^{\mathrm{n}+1} \leq 1.5 \Delta t^{\mathrm{n}}
$$

where $\Delta t^{\mathrm{n}+1}$ is the time increment at step number $n+1$.

Previous investigations by Zienkiewicz and Cormeau (1974) and Cormeau (1975) have shown that none of these empirical criteria are entirely satisfactory and none could prevent some forms of instability.

The determination of the time-increment parameter $\tau$ is one of the major problems in visco-plastic analysis, especially under three-dimensional conditions. A large value of $\tau$ will result in numerical instability, while a small value of $\tau$ will give a stable result, but will result in computation inefficiency. Currently, there are no satisfactory criteria available to prevent numerical instability in the doubleyield surface case. Moreover, it is very time-consuming to conduct three-dimensional visco-plastic analyses using the DYSCP model because the stiffness matrix is nonsymmetric due to non-associative flow rule of the creep process. In order to balance between the numerical instability and computation efficiency, a trial and error method was used in this case to optimise the value of $\tau$.

In this study, for one value of $\tau$, an analysis typically ran for a couple of days before any possible unstable results was noticed. Therefore, it was unrealistic to try many different values of $\tau$. Three values of $\tau(\tau=0.05$, 0.02 , and 0.01 ) have been selected. A $\tau$ value of 0.05 was 
used first and unstable results were found. A $\tau$ value of 0.01 gave stable results, but was very time-consuming. Finally a $\tau$ value of 0.02 was found to be a relatively optimum value for the Pisa soil and was used in this study. A typical analysis ran for about five weeks using a $\tau$ value of 0.02 .

\section{HISTORIC TILTING AND MAJOR DISTURBANCES OF PISA TOWER}

The overview of the Pisa tower, its construction history, and the soil profile underneath the tower can be found in Jamiolkowski et al. (1993), Calabresi et al. (1992), Burland and Potts (1995), and Bai (1998). The subsurface condition under the Pisa tower can be grouped into three distinct formations: the $10 \mathrm{~m}$ thick Formation A consists of rather variable sandy and clayey silts. The material in the south side of the tower appears to be more silty and clayey than in the north side. This is believed to be a major factor in causing the tower to lean towards the south; the $30 \mathrm{~m}$ thick Formation B contains predominantly clay. It includes the upper clay or Pancone clay (B1 to $\mathrm{B} 3$ ), the intermediate clay (B4 to B5), the intermediate sand (B6), and the lower clay (B7 to B10); and Formation $\mathrm{C}$, encountered at a depth of $40 \mathrm{~m}$, contains slightly silty sand. It extends to a depth greater than the deepest boring.

Figure 1 shows the tilting history of the tower. The tilting history and major disturbances of the tower are presented in detail since they are crucial to the calibration of the numerical model in simulating the tilting history of the tower during and after its construction. Figure 1 indicates that significant tilting of the tower occurred only after the second construction stage. When the bell chamber was finished, the tower tilted about 1.6 degrees. By 1550 , tilting had increased dramatically, up to 4.7 degrees. What happened during this time period is not clear. One possible explanation for this discontinuity is the possibility of a foundation material failure in some areas around the south side. After the tower reached its full height, it was very possible that very high stress concentrations at the south side of the footing brought the footing material to a state of failure. Thus, the tower rotated towards the south side to reflect this effect.

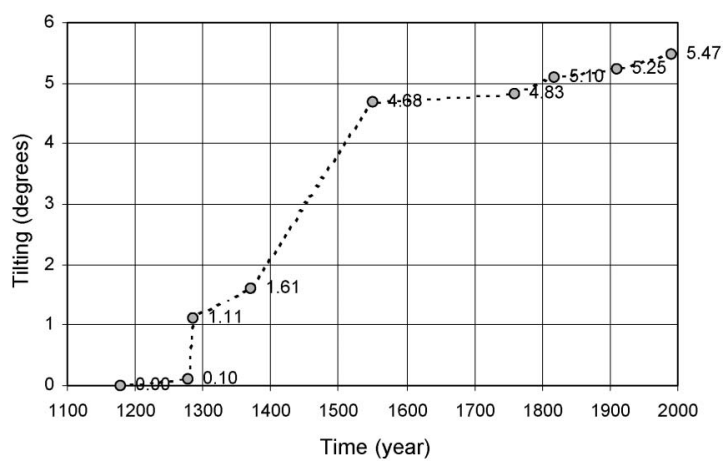

Fig. 1. Tilting history of the tower (observed)
Another possible explanation for this discontinuity is that after the tower reached its full height, leaning instability proposed by Burland and Potts (1995) occurred, which caused the tower to rotate around a centre above its foundation. This kind of pure rotation amplified the tower's inclination.

During the Second World War, Pisa City was subjected to substantial destruction from heavy bombing raids. Some artistic treasures, including the Piazza dei Miracoli, were seriously damaged (Verlag La Torre s.r.1., 1984). Even though there is no detailed record available related to direct damage of the tower, it is almost certain that the tower suffered from bomb explosion shocks. This type of dynamic influence may have caused the tower to tilt even more.

Among the recorded events, the excavation of the catino in 1834 appears to have caused an increase in tilting by 0.5 degrees. The bottom of the excavation was below the ground-water table and a substantial flow of water poured out on the south side of the tower, carrying with it, noticeable quantities of solid material.

For most of this century, the inclination of the tower has been increasing, but these changes of inclination are extremely small in comparison with those that occurred during and immediately following the construction period. Figure 2 shows the tilting in the N-S plane since 1911. Four major perturbations can be found. The current rate of tower inclination has doubled since the 1930's. The tower is very sensitive even to the smallest ground disturbance.

The systematic monitoring of the tower shows that temperature changes also have some influence on the tower's movement. Figure 3 shows daily movements of the tower obtained by means of an inclinometer called the Girometti-Bonecchi Pendulum. The tower expands as the sun heats it. It rotates in a loop as the sun moves across the sky. Some of this motion causes the tower to "screw" into the ground (Wheeler, 1995).

A study by Croce et al. (1981) shows that apart from the tilting of the tower itself, the whole Pisa plain is sub-

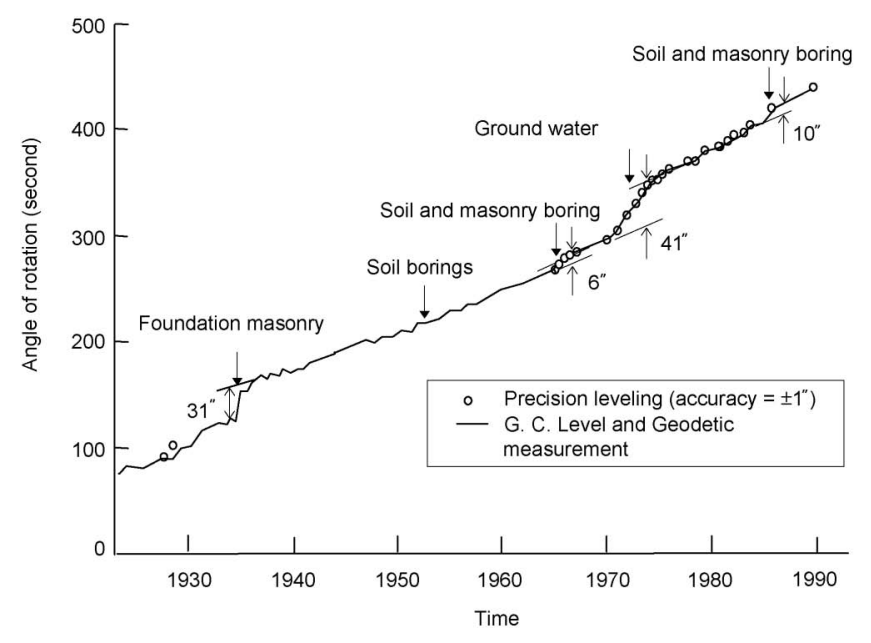

Fig. 2. Change in inclination of the foundation since 1911 (modified after Jamiokowski et al., 1993) 
siding, as shown in Fig. 4. The differential subsidence occurring in the square might contribute to the present tilting of the tower. Other disturbances, such as earthquakes, wind, traffic, and visitors, also increase the tilting of the tower (Grabe and Gudehus, 1992).

It must be kept in mind that the actual situation of the tower is very complex. There are many physical disturbances in the history of the tower that may account for its inclination. Moreover, there may be more than one mechanism controlling its deformation behaviour. It is almost impossible to account for all aspects in a single constitutive model. Nevertheless, sample tests on the Pisa clay already show the importance of its creep behaviour. It is worthwhile to determine how much of this characteristic contributes to the deformation of the tower.

The present study focuses on the creep deformation of the foundation soil below the Pisa tower. Creep is believed to be the main mechanism of deformation. Other effects, such as daily oscillation of the tower due to heat-

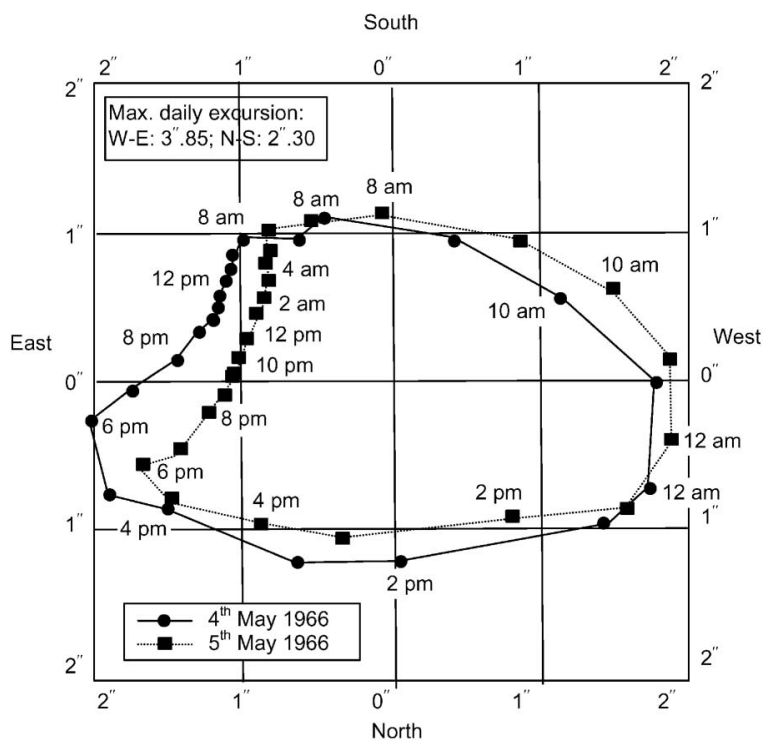

Fig. 3. Daily movement of the tower due to change of temperature (modified after Jamiolkowski et al., 1993)

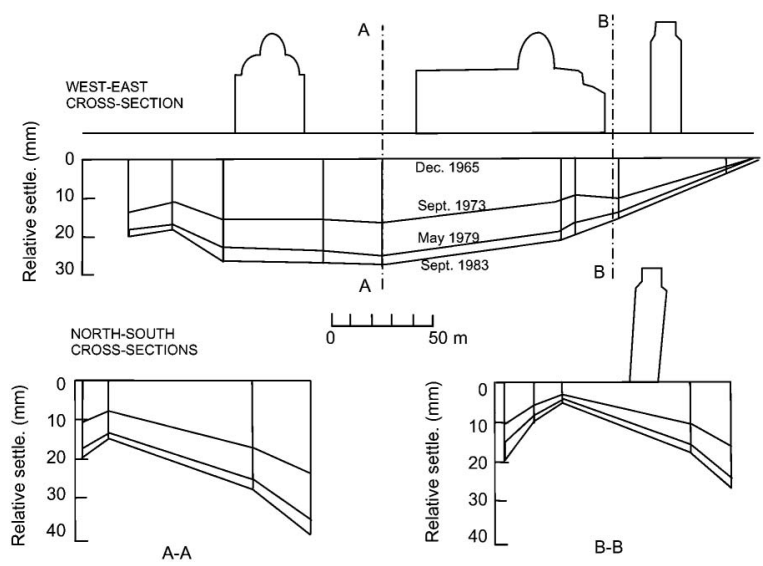

Fig. 4. Relative settlements over the Piazza dei Miracoli (modified after AGI 1994) ing by the sun, as shown in Fig. 3, and the effect of excavation to settlement of the general area, as shown in Fig. 4 , are not considered. The current approach assumes the predominant deformation is tiling of the tower in the north-south direction.

\section{CREEP ANALYSIS WITHOUT MODELLING THE TOWER STRUCTURE}

Due to the stress path dependence of the material behaviour, a realistic loading sequence is a fundamental requirement for obtaining reasonable results from numerical modelling. In this study, the loading sequence is comprised of an initial switch on gravity analysis to obtain pre-existing stress field prior to the construction of the tower and subsequent application of loads due to the construction of the tower. In order to obtain more accurate initial stresses and yielding surfaces for the plasticity model before the construction of the tower, the switch on gravity process was carried out in 10 steps by applying 10 $\%$ of the gravity load for each time. Then, displacements and the strains were both set to zero to give an initial configuration of the soil. The tower loads were then applied in accordance to the construction history. The soil material properties that were used are the same as those utilized for the two-dimensional analyses and can be found in Bai et al., 2008.

\section{Finite Element Model}

Figure 5 shows the three-dimensional mesh without the tower, which is the half of the foundation soil along the $\mathrm{N}-\mathrm{S}$ direction and by neglecting deformation in the E-W direction. The mesh contains a total of 708 elements. It extends vertically to $40 \mathrm{~m}$, with a horizontal radius of 60 $\mathrm{m}$. Two different types of elements were used in this study: a 20-node block element, and an 8-node block element, as shown in Figs. 6 and 7, respectively. The computer implementation showed that the 20 -node block element gave very large of degrees of freedom. Therefore, the 20-node element was used only for a comparative study on the effect of element type. The 8-node block elements with a total of 949 nodes and 2345 degrees of freedom were used. The inclined soil layer in Formation A was modelled using the inclined 8-node block elements.



Fig. 5. Three-dimensional finite element model of Pisa foundation 


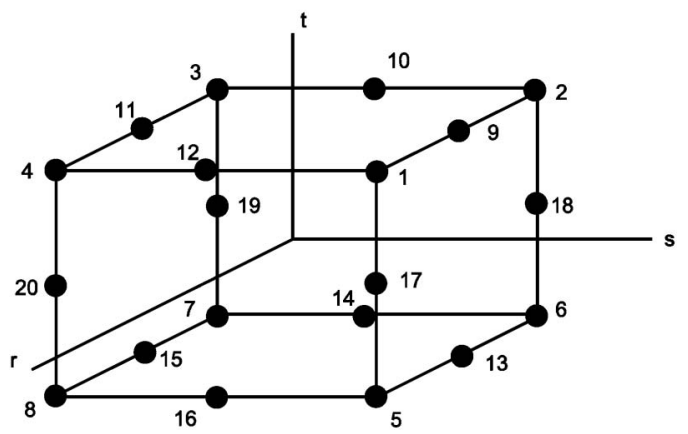

Fig. 6. 20-node rectangular element for $3 D$ analysis

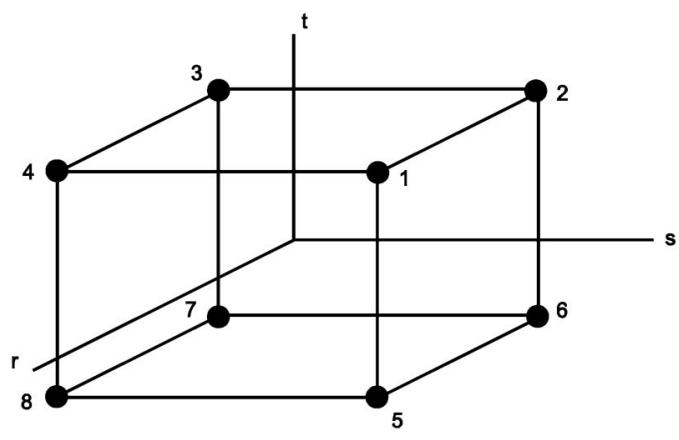

Fig. 7. 8-node rectangular element for 3D analysis

The horizontally sliced 8-node block elements were used for the other soil layers. The tower footing was modelled as a ring-shaped rigid plate.

For the purpose of the analysis, a coordinate system is selected with the origin at the lower left corner, which is $45 \mathrm{~m}$ below the original ground level, $80 \mathrm{~m}$ north from the tower axis and $5 \mathrm{~m}$ in front of the tower axis, as shown in Fig. 5 (not in scale). The formation $C$ (dense sand), encountered at an elevation of $40 \mathrm{~m}$ below the ground surface, is assumed to be unaffected by the construction of the tower. Therefore, the bottom boundary of the finite element mesh is fixed at this depth. Vertical roller boundaries with zero horizontal displacements in the $\mathrm{X}$ and $\mathrm{Y}$ directions are defined at the vertical surface with a horizontal radius of $60 \mathrm{~m}$. The vertical roller boundaries with zero horizontal displacement in the $\mathrm{Y}$ direction are defined at the vertical surface along the N-S direction and through the tower's axis.

After the switch on gravity process, to account for the tower's weight and inclination, the load and overturning moment were applied to the mesh. Table 1 shows the loading history and overturning moment. The loads were reduced to an amount of $11589 \mathrm{kN}$ due to the weight of soil excavated for the foundation of the tower. Then the reduced tower weight was converted to two loads acting at $6.02 \mathrm{~m}$ south and north from the tower centre. For each loading step, a time value based on the real history was added to let the soil creep. The time period for each stage was specified in terms of years. The loading conditions for three-dimensional analysis are shown in Table 2.
Table 1. Weight, overturning moment and rigid tilt versus time

\begin{tabular}{c|c|c|c}
\hline Year & Weight $(\mathrm{MN})$ & Moment $(\mathrm{MNm})$ & Tilt (degree) \\
\hline 1178 & 94.80 & - & - \\
$1272-1278$ & 137.28 & 5.51 & 0.103 \\
1285 & 137.28 & 59.99 & 1.112 \\
$1360-1370$ & 144.53 & 97.7 & 1.611 \\
1550 & 144.53 & 284.72 & 4.684 \\
1758 & 144.53 & 293.54 & 4.831 \\
1817 & 144.53 & 310.98 & 5.103 \\
1911 & 144.53 & 318.98 & 5.246 \\
1990 & 144.53 & 332.56 & 5.469 \\
\hline
\end{tabular}

Table 2. Three-dimensional loading increments

\begin{tabular}{|c|c|c|c|c|c|}
\hline \multirow{2}{*}{ Year } & \multicolumn{2}{|c|}{ increment } & \multicolumn{2}{|c|}{$\Delta p(\mathrm{kPa})$} & \multirow{2}{*}{$\begin{array}{l}\text { Creep time } \\
\quad \text { (years) }\end{array}$} \\
\hline & $\begin{array}{l}\text { Weight } \\
\text { (MN) }\end{array}$ & $\begin{array}{c}\text { moment } \\
(\mathrm{MNm})\end{array}$ & at North & at South & \\
\hline 1173 & 32.211 & & 8052.8 & 8052.8 & - \\
\hline 1173 & 39.411 & & 9852.8 & 9852.8 & \\
\hline $1173-1178$ & & & - & - & 6 (stage 1) \\
\hline $1178-1272$ & & & - & - & 94 \\
\hline 1272 & 42.48 & 5.51 & 10391.2 & 10848.8 & - \\
\hline $1272-1278$ & & & - & - & 6 (stage 2 ) \\
\hline 1278 & & 27.185 & -1128.9 & 1128.9 & - \\
\hline 1278 & & 27.185 & -1128.9 & 1128.9 & - \\
\hline $1278-1285$ & & & & & 7 \\
\hline 1285 & & 18.91 & -785.3 & 785.3 & - \\
\hline 1285 & & 18.91 & -785.3 & 785.3 & - \\
\hline $1285-1360$ & & & - & - & 75 \\
\hline $1360-1370$ & & & - & - & 10 (stage 3 ) \\
\hline 1370 & 7.25 & & 1812.5 & 1812.5 & - \\
\hline 1370 & & 31.17 & -1294.4 & 1294.4 & - \\
\hline $1370-1430$ & & & - & - & 60 \\
\hline 1430 & & 62.34 & -2588.9 & 2588.9 & - \\
\hline $1430-1490$ & & & - & - & 60 \\
\hline 1490 & & 62.34 & -2588.9 & 2588.9 & - \\
\hline $1490-1550$ & & & - & - & 60 \\
\hline 1550 & & 31.17 & -1294.4 & 1294.4 & - \\
\hline 1550 & & 4.41 & -183.1 & 183.1 & - \\
\hline $1550-1758$ & & & - & - & 208 \\
\hline 1758 & & 4.41 & -183.1 & 183.1 & - \\
\hline 1758 & & 8.31 & -362.1 & 362.1 & - \\
\hline $1758-1817$ & & & - & - & 59 \\
\hline 1817 & & 8.31 & -362.1 & 362.1 & - \\
\hline 1817 & & 4.41 & -183.1 & 183.1 & - \\
\hline $1817-1911$ & & & - & - & 94 \\
\hline 1911 & & 4.41 & -183.1 & 183.1 & - \\
\hline 1911 & & 6.79 & -282.0 & 282.0 & - \\
\hline 1911-1990 & & & - & - & 79 \\
\hline 1990 & & 6.79 & -282.0 & 282.0 & (Stage 4) \\
\hline
\end{tabular}

In order to investigate the creep effects on the deformation characteristics and the stress response of the soil beneath the foundation, both plastic and creep analyses using 20-node and 8-node block elements were carried out. The results are discussed in the following sections.

\section{Results of the Analysis}

Laboratory tests have shown that creep is important in soil layers $A_{1}$ and $B_{1}$ (Mitchell and Soga, 1995). Therefore, creep effects on the stress response were studied in detail in these layers, as shown in Fig. 8. This figure also shows the locations of four elements. Elements 503 and 


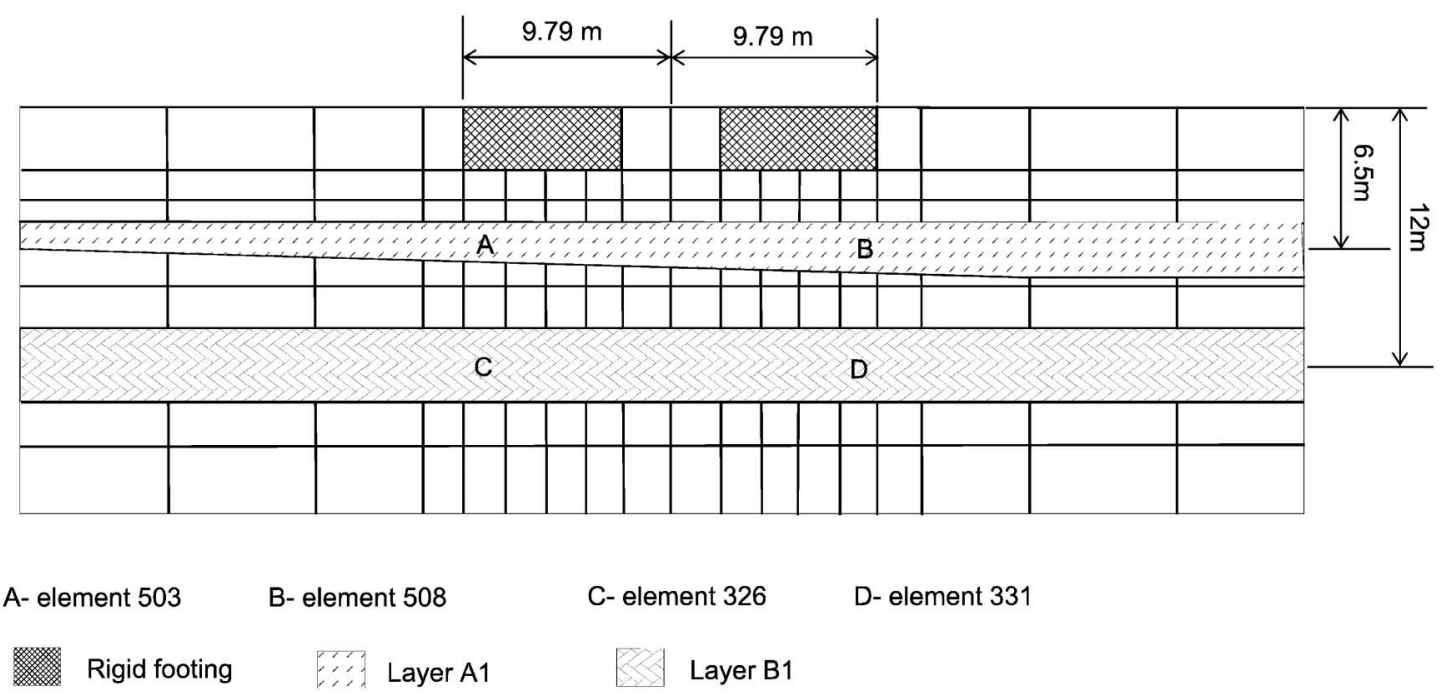

Fig. 8. Three-dimensional mesh of Pisa foundation (part)

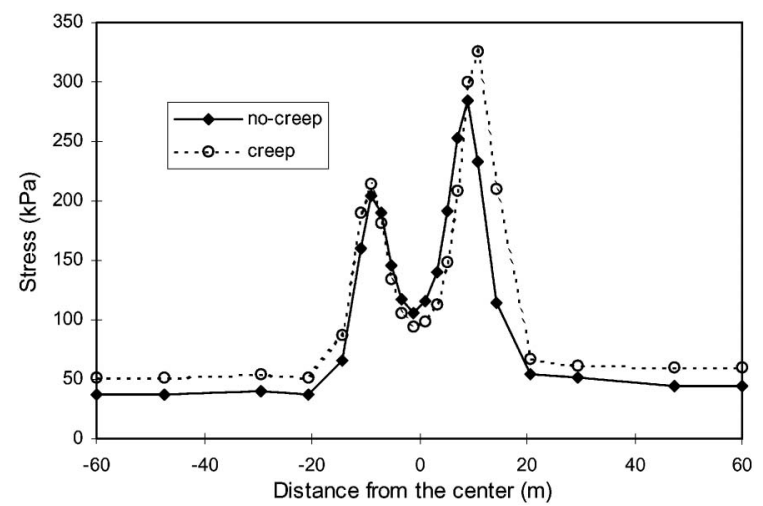

Fig. 9(a). Mean stress distribution at depth of $6.5 \mathrm{~m}$ (Layer A1)

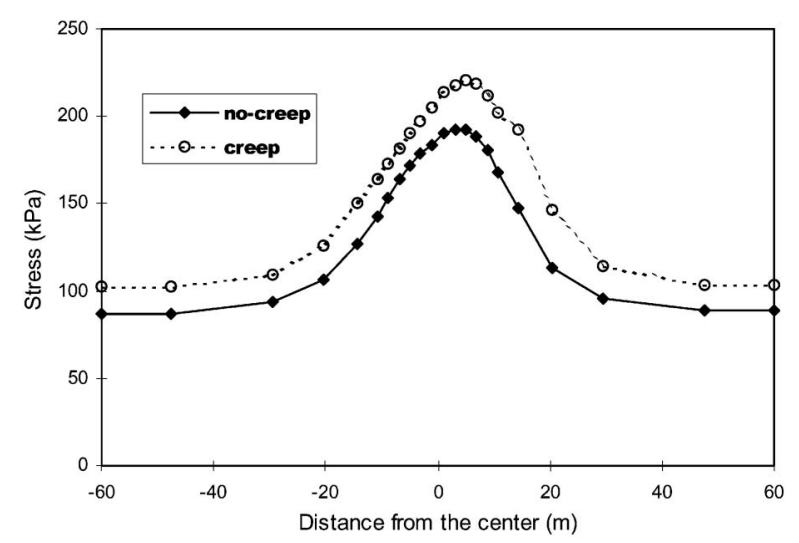

Fig. 9(b). Mean stress distribution at depth of $12 \mathrm{~m}$ (Layer B1)

508 are in Layer $\mathrm{A}_{1}, 6.5 \mathrm{~m}$ deep and located underneath the north and south edges of the footing, respectively; elements 326 and 331 are in Layer $B_{1}, 12 \mathrm{~m}$ deep and located underneath the north and south edges of the footing, respectively. These are monitoring points in the numerical model where stress conditions will be studied in more detail.

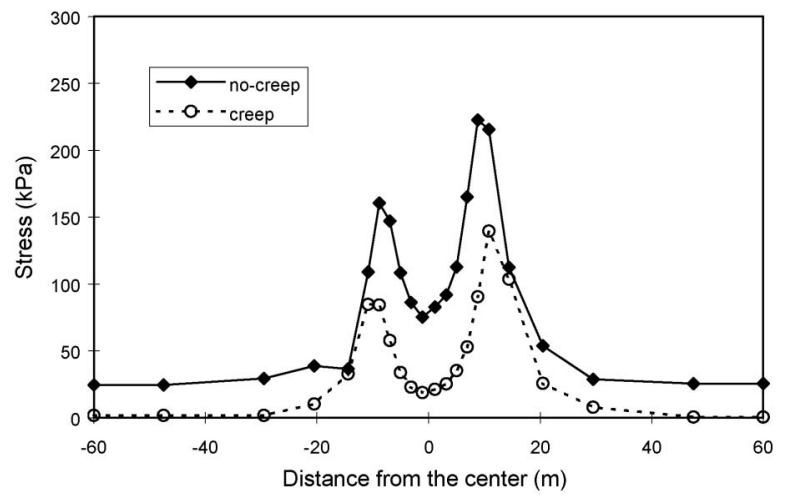

Fig. 10(a). Deviatoric stress distribution at depth of $6.5 \mathrm{~m}$ (Layer A1)

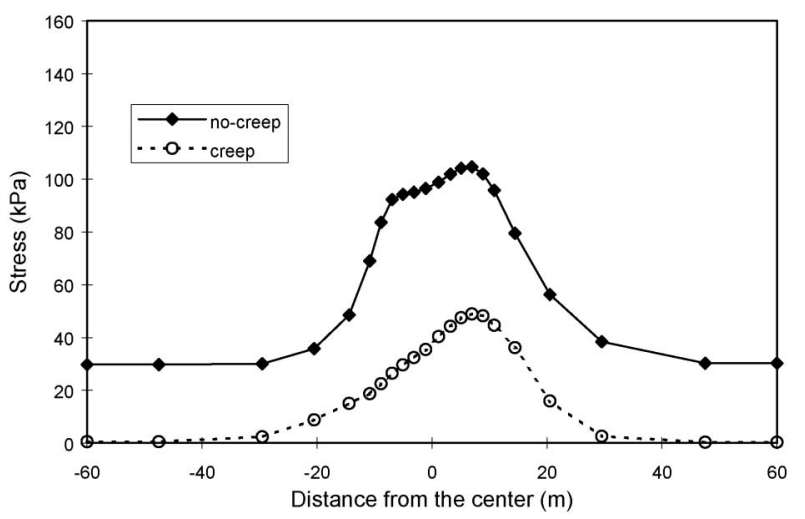

Fig. 10(b). Deviatoric stress distribution at depth of 12 m (Layer B1)

Figures 9(a) and (b) show the mean effective stress distributions at $6.5 \mathrm{~m}$ and $12 \mathrm{~m}$ deep, respectively. To study the effect of creep, both creep analysis and no creep analysis were carried out. Results of creep analysis are presented for the year 1998. For no-creep cases, only elasto-plastic analyses were carried out. The deformation was considered to be instantaneous and no time effect was 


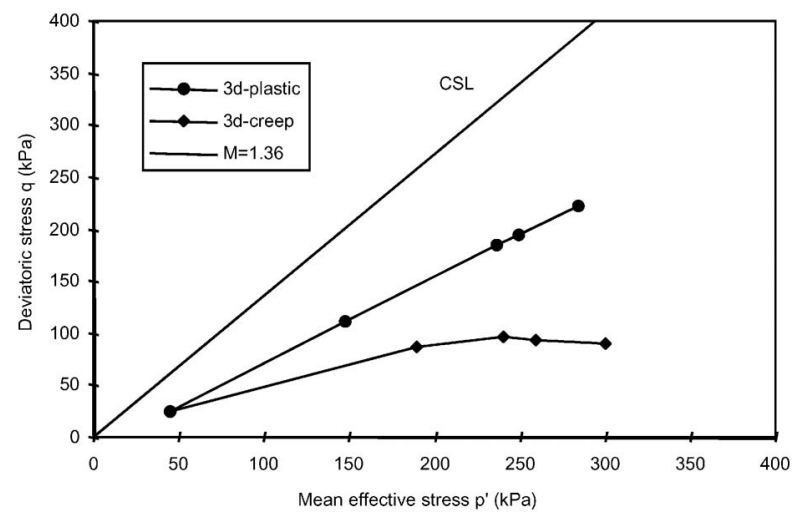

Fig. 11(a). Stress path at $9.8 \mathrm{~m}$ south of the footing center, $6.5 \mathrm{~m}$ (Clayey silt A1)

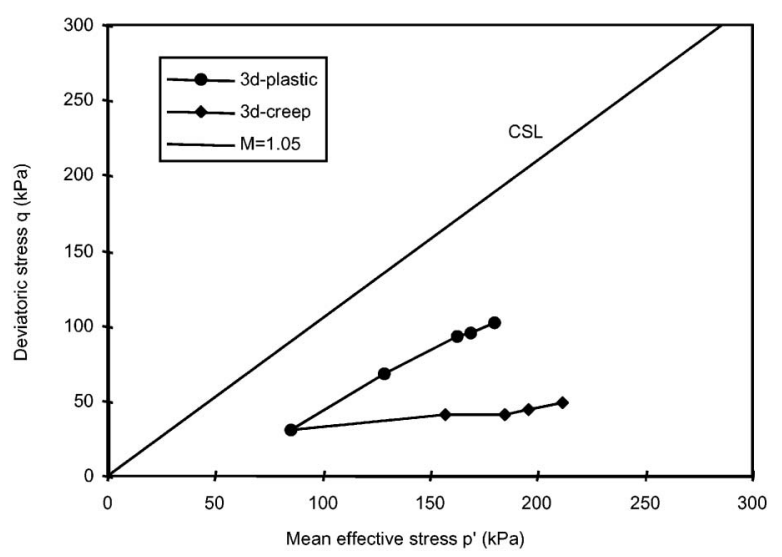

Fig. 11(b). Stress path at $9.8 \mathrm{~m}$ south of the footig center, $12 \mathrm{~m}$ (Upper clay B1)

considered. For layer $\mathrm{A}_{1}$, creep increases mean effective stresses except underneath the footing area. The maximum increase in mean effective stresses is about $84 \%$, which occurs at $14 \mathrm{~m}$ south from the footing centre. For layer $\mathrm{B}_{1}$, creep increases the mean effective stress with the maximum value of about $31 \%$, which also occurs at $14 \mathrm{~m}$ south of the footing centre.

Deviatoric stress distributions at both $6.5 \mathrm{~m}$ and $12 \mathrm{~m}$ depths (Fig. 10) show that creep decreases the shear stresses especially within the footing area, up to $59 \%$ decrease in layer $A_{1}$ and $53 \%$ in layer $B_{1}$. Outside the footing area, creep drives deviatoric stress to almost zero, which is equivalent to the hydrostatic stress condition.

Figure 11 shows the $p^{\prime}-q$ plots at the centre of elements 508 and 331, which are located at the south edge of the footing, at $6.5 \mathrm{~m}$ and $12 \mathrm{~m}$ depths, respectively. It can be seen that elasto-plastic deformation causes a more or less proportional increase in $p$ and $q$, thus staying close to the critical state line (CSL). However, creep causes the stress states to move away from the critical state line, thus making the soil less susceptible to failure. This phenomenon has been reported by Morsy et al. (1995) in which redistribution of stresses during creep results in lower mobilized shear stresses provided that the load level is not high enough to cause tertiary creep and creep rupture.

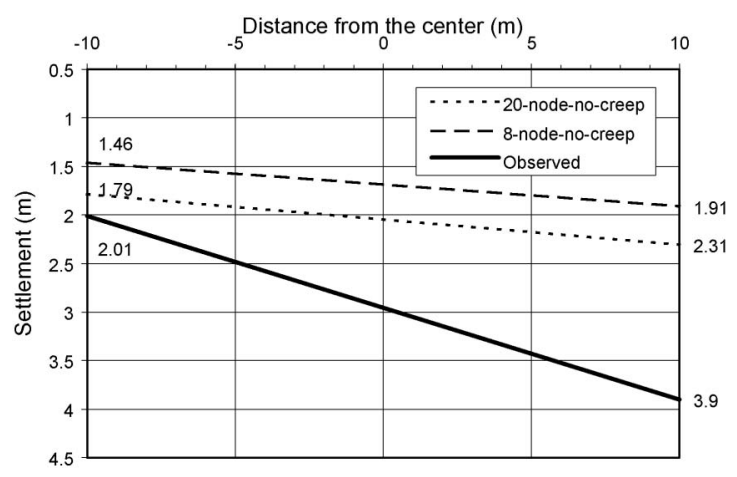

Fig. 12. Comparison for the settlement of the footing under different element types (plastic analysis)

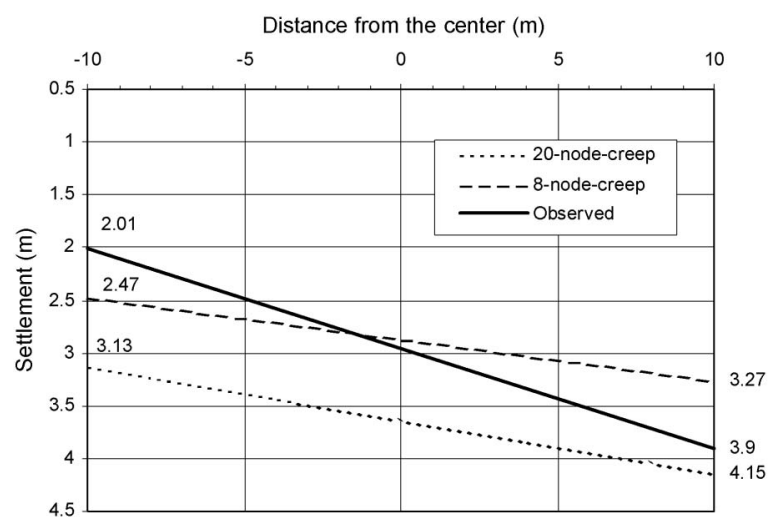

Fig. 13. Comparison for the settlement of the footing under different element types (creep analysis)

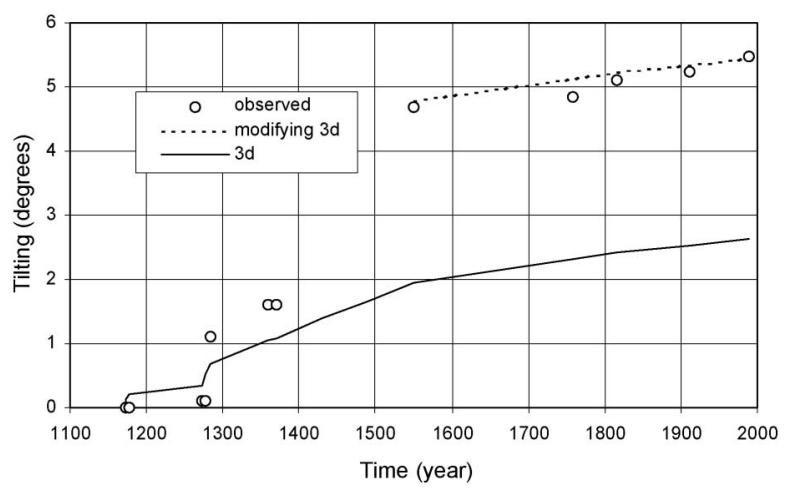

Fig. 14. Calculated tilting history of the tower

Figures 12 and 13 show the final settlement of the footing from the results of creep and no-creep analyses using both 20 -node and 8-node block elements, respectively. For 20-node block elements, creep analysis gives 3.0 degrees tilting and $3.6 \mathrm{~m}$ settlement and no-creep analysis gives 1.5 degrees tilting and $2.1 \mathrm{~m}$ settlement, which suggests that the creep effect accounts for 1.5 degrees of the tilting and $1.5 \mathrm{~m}$ of the settlement. Using the 8-node block elements, creep analysis gives 2.5 degrees tilting, of which creep accounts for 1.2 degrees.

Figure 14 shows the tilting versus time relationship 
from creep analysis using 8-node block elements since 8node block elements can model creep deformation of the foundation soil effectively and it is computationally more efficient than the 20-node element. Numerical results can reasonably follow the tilting history during the construction period, but significantly under-predict the tilting angle after that. If part of the simulated curve after year 1550 is shifted vertically, one can see that numerical simulation could follow the observed data fairly well. This suggests that after considering some significant physical disturbances, creep analysis could still simulate the tilting history during the last four centuries.

\section{SENSITIVITY ANALYSES}

In order to investigate the possibility of improving the calculated tilting angle by changing the values of the material parameters in the DYSCP model, sensitivity analyses were conducted for the Singh and Mitchell creep parameters $\bar{\alpha}$ and $m$ for layer $\mathrm{A}_{1}$. This is guided by the results of the two-dimensional parameter sensitivity study conducted by Bai (1998).

The Singh and Mitchell creep parameter $m$ controls the rate at which the strain rate decreases with time, as given by Eq. (4). The undrained triaxial tests conducted by Mitchell and Soga (1995) gave $m$ values from 0.77 to 0.96 with a mean value of 0.89 for soil layer $A_{1}$. In this study, the effect of the parameter $m$ on the total tilting angle was investigated through three analyses using $m$ values of $0.75,0.89$, and 0.95 while keeping the other parameters the same values. The results give a concave upward curve in the tilting angle versus $m$ plot as shown in Fig. 15. A value of 0.89 of $m$ gives the smallest tilting, while a value of 0.75 of $m$ gives the largest tilting. The difference in tilting angle is within 0.5 degrees.

The Singh and Mitchell creep parameter $\bar{\alpha}$ indicates the stress-intensity effect on the creep rate. Mitchell and Soga's (1995) tests gave $\bar{\alpha}$ values from 5.07 to 6.29 with a mean value of 5.81 for soil layer $\mathrm{A}_{1}$. Three analyses were carried out using $\bar{\alpha}$ values of $3.81,5.81$, and 7.81 to study the effect of this parameter. The results give a slightly concave downward curve in the tilting angle versus $\bar{\alpha}$ plot, as shown in Fig. 16. A value of $\bar{\alpha}$ of 3.81 gives the smallest tilting, while a value of $\bar{\alpha}$ of 7.81 gives the biggest tilting, but the difference in final tilting is only within a difference of 0.2 degrees.

As in the context for the two-dimensional case, the deformation behaviour of the soil beneath the foundation is not dominated by any single model parameter. By changing the values of material parameters, such as the Singh and Mitchell parameters $\bar{\alpha}$ and $m$, the total tilting angle only changes up to 0.5 degrees. This helps to clarify that the actual 5.5 degrees tilting angle cannot be obtained, even through a fully three-dimensional creep analysis. There must be some other reasons that have also contributed to the tilting of the tower, such as physical disturbances and other deformation mechanisms, which could not be quantified in the current numerical model.

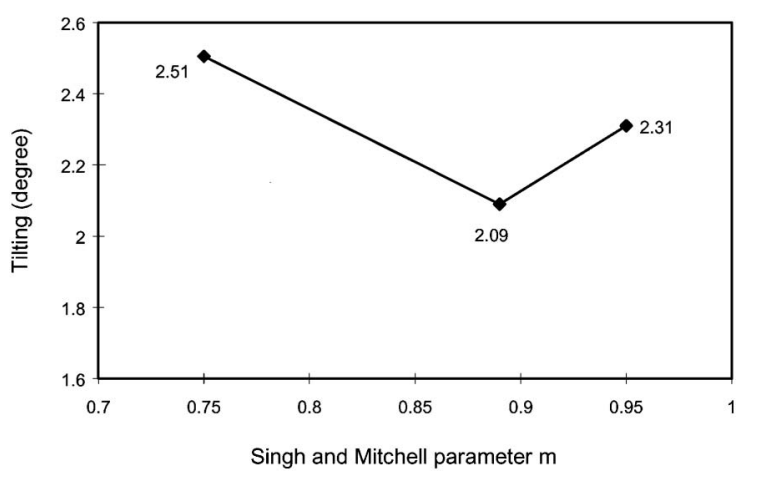

Fig. 15. Influence of Singh and Mitchell parameter $m$ on tilting angle

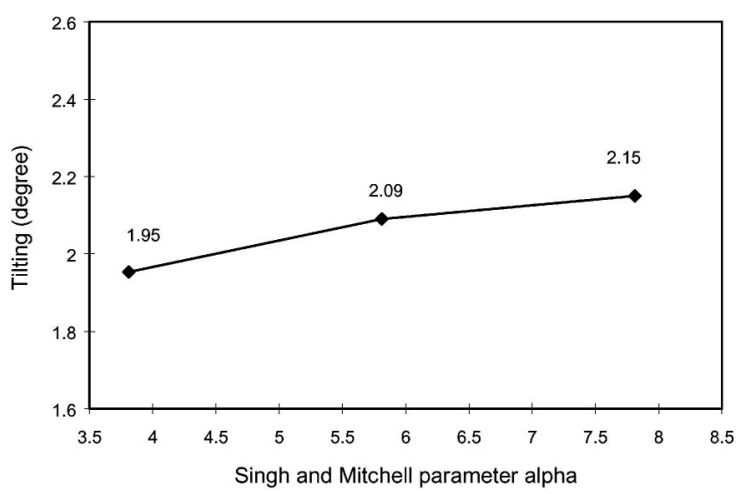

Fig. 16. Influence of Singh and Mitchell parameter alpha on tilting angle

\section{CREEP ANALYSIS INCLUDING THE TOWER STRUCTURE}

In order to avoid applying load and overturning moment directly to the tower's foundation, a creep analysis of the Pisa soil including the tower structure was conducted under three-dimensional conditions. The finite element mesh, shown in Fig. 17, consists of 828 8-node block elements with a total number of 1124 nodes. The soil was modelled using the same mesh as shown in Fig. 5 . The tower was modelled by adding 120 additional elements. Roller boundary was used for all vertical sides and fully fixed boundary was used for the base of the finite element mesh. It was assumed to have a uniform geometry and the same inner and outer diameters of $4.5 \mathrm{~m}$ and $19.58 \mathrm{~m}$, respectively. An equivalent unit weight $\gamma$ was obtained through the volume and the weight at a different time period. A linear elastic model was used for the tower material, since only the stress in the soil beneath the foundation was of interest in this study.

The loading sequence comprised of two parts: (a) a switch on gravity steps to obtain the initial stress field using the same process as the without the tower structure case; and (b) subsequent layer construction to simulate the corresponding tower construction according to the actual construction process. Nodal coordinates were updated after each time increment. During the construction period, elements were added instantly at each stage and 
the gravity loading was applied at 10 steps by applying $10 \%$ each time in order to improve the accuracy of calculations. In modelling the first construction stage, the footing and tower elements were added up to $29.8 \mathrm{~m}$ above the ground as shown in Fig. 18; then the soil underwent creep until the beginning of the second stage. At the second stage, the tower elements were added from $29.8 \mathrm{~m}$ to $47.9 \mathrm{~m}$. In order to initiate a southward leaning of the tower at this stage, eight weaker elements that were close to the south edge of the footing were introduced. These weak elements were given two to three orders of magnitude of lower stiffness. The last construction stage was modelled by adding up the tower elements from 47.9 $\mathrm{m}$ to $55.4 \mathrm{~m}$. After this, gravity loading was not applied anymore to the model. The soil beneath the foundation was allowed to creep until the present time.

Figure 19(a) plots the tilting history of the tower with eight weak elements in the soil around the southern edge of the footing. Numerical results can follow the tilting

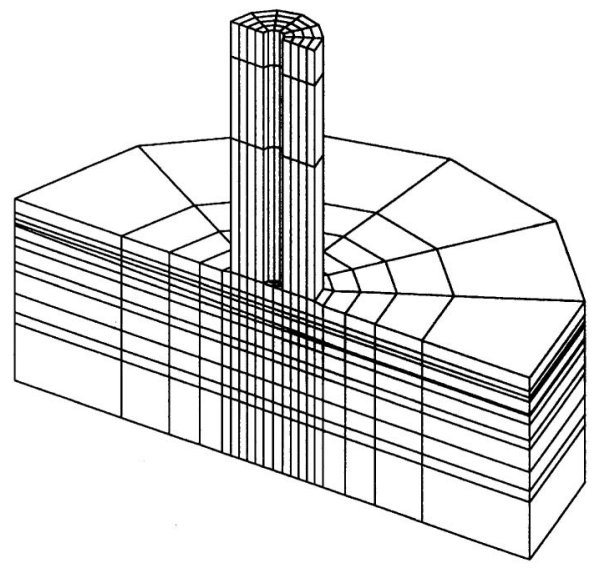

Fig. 17. Three-dimensional finite element model of Pisa Tower and its foundation history closely until the end of the construction stage (year 1370), but under-predict the tilting angle after that time. The numerical results do not indicate a sudden jump of tilting from years 1370 to 1550 . If the calculated tilting after 1550 was shifted up by 2.5 degrees, it provides a very close approximation of the observed data as

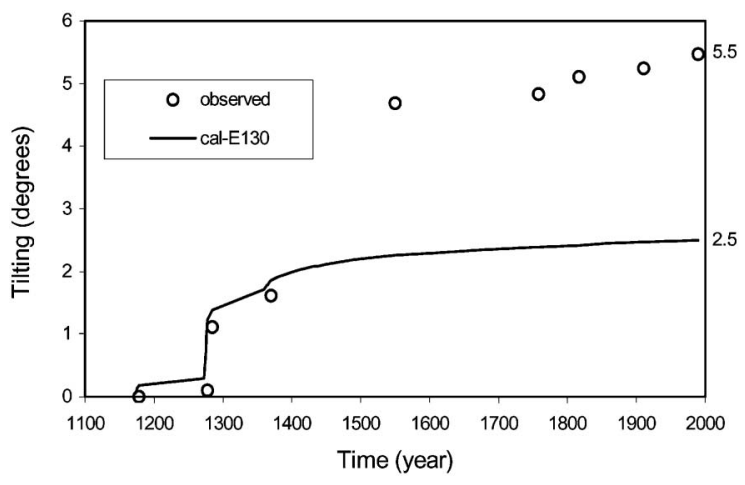

Fig. 19(a). Tilting history of the tower

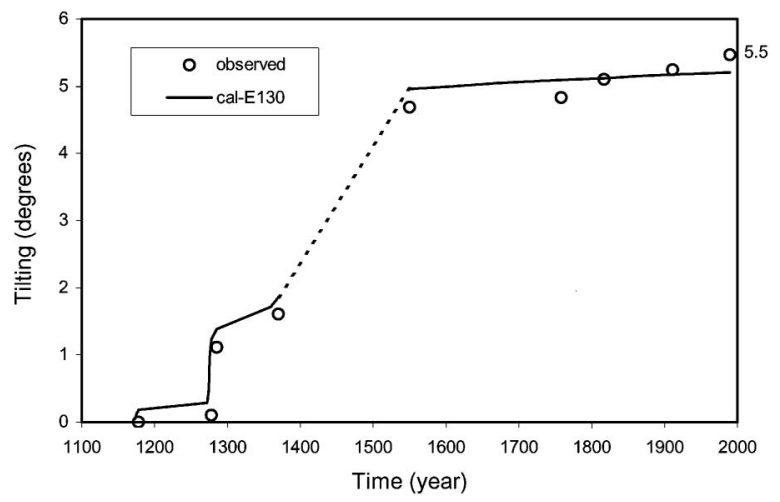

Fig. 19(b). Tilting history of the tower after modification

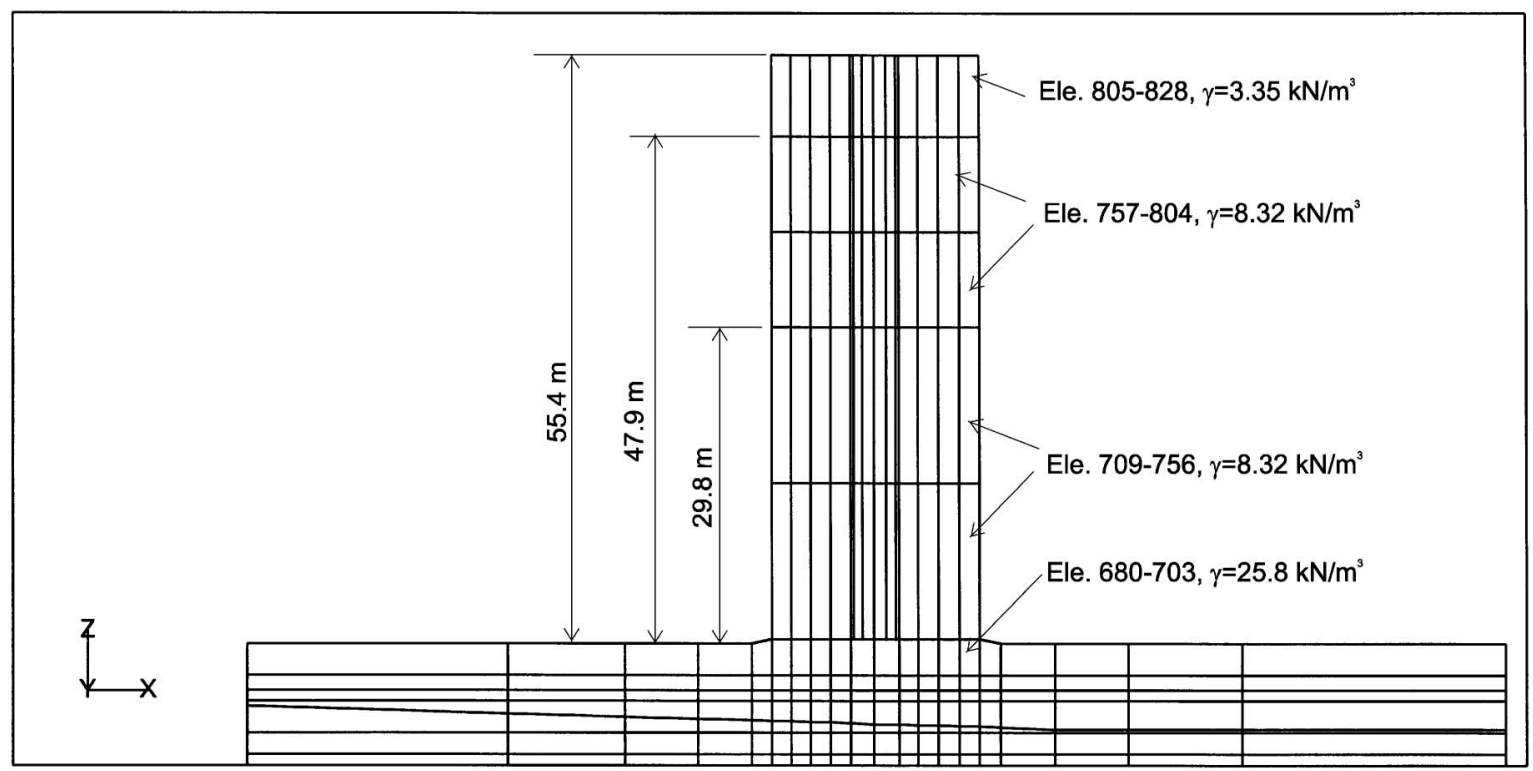

Fig. 18. Three-dimensional finite element model of Pisa Tower and its foundation (part) 


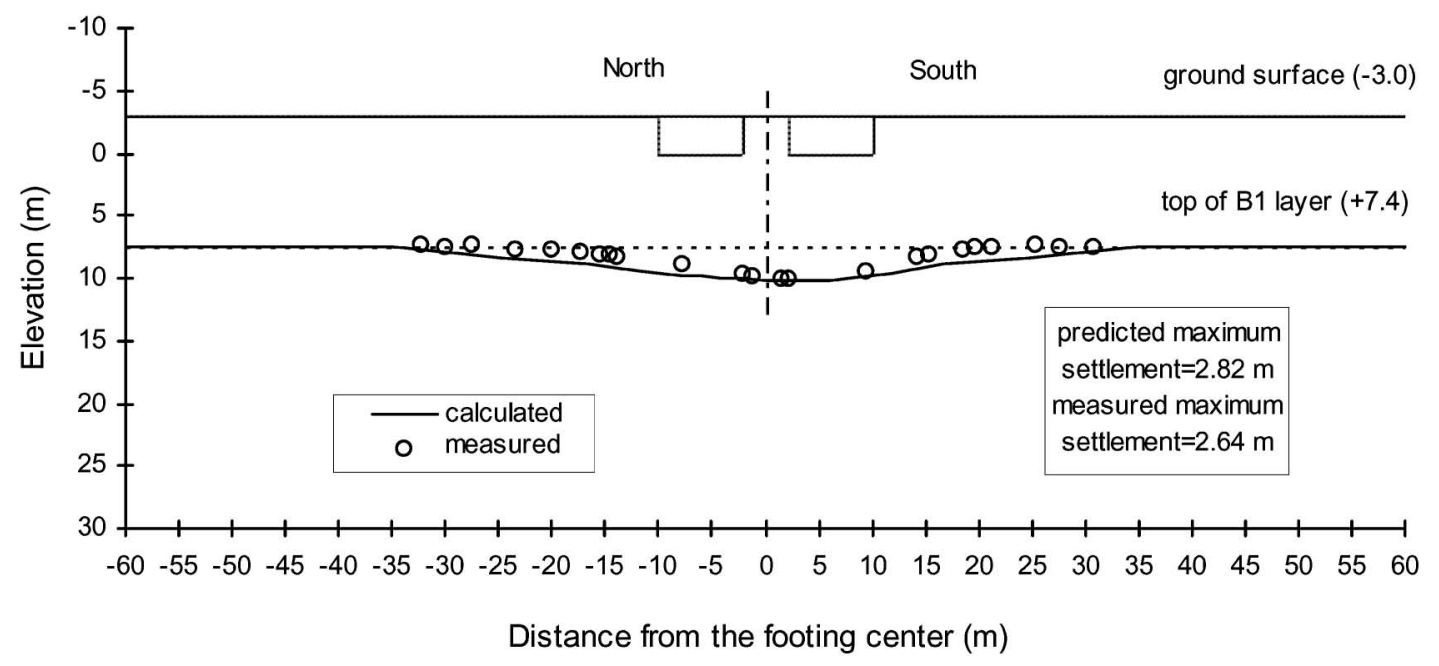

Fig. 20. Predicted final settlement profile at the top of the upper clay layers

shown in Fig. 19(b). This suggests that between the years 1370 and 1550 , it is possible that tilting of the tower was caused by other external effects aside from creeping of the foundation soil. During this period of time, the tower had tilted about 1 degree while in the period of about 80 years between 1370 and 1550 , the tower had tilted 3 degrees. This disproportional rate of tilting cannot be explained by the present model.

Figure 20 presents both the calculated settlement profile and the measured data from borehole tests (Calabresi et al., 1992) along the N-S cross section on the top of the upper clay layers, at $10.4 \mathrm{~m}$ depth below the ground surface. The calculated settlement profile marches the measured data very well. The calculated maximum settlement of $2.82 \mathrm{~m}$ is very close to the measured value of $2.64 \mathrm{~m}$. The calculated settlement trough has a radius bigger than the measured one. This discrepancy may be due to local failure that occurred around the south side of the footing or numerical effects due to larger finite elements used in this region. If the footing material in some areas were in a state of failure, the stiffness of the whole footing would be decreased. Thus, the settlement trough beneath the footing would be smaller in comparison with this if there had not been any failure of footing material. On the other hand, the accuracy of the prediction might have improved if smaller elements were adopted.

\section{SUMMARY AND CONCLUSIONS}

This study has investigated the creep effects on the deformation behaviour under three-dimensional conditions and the stress response of the soil underneath the Pisa Tower. It has been found that two-dimensional analyses can not provide a good representation of stress distributions in the soil. The differences in stresses between two and three-dimensional conditions and between creep and no-creep case are too prominent to be neglected. Three-dimensional creep analysis, although it is very time consuming, is necessary in order to obtain more realistic results.
Results from the three-dimensional creep analysis can predict the tilting history within reasonable accuracy during the construction period and illustrate more or less the same trend for the last four centuries. The three dimensional model is also capable of calculating the settlement profile on top of the upper clay layers with fair accuracy. The calculated maximum settlement of $2.82 \mathrm{~m}$ is very close to the measured value of $2.64 \mathrm{~m}$.

From the three-dimensional creep analyses, a maximum tilting of 3.0 degrees were calculated, of which 1.5 degrees was due to creep. It is clear that the actual 5.5 degrees of tilting cannot be obtained by simply changing the values of the material parameters in the DYSCP model. Other reasons probably have contributed to the tilting, which cannot be simply quantified due to the complexity in the titling history of the tower. In summary, the 5.5 degrees tilting is the total result of more than one cause. No single numerical model is able to consider all of them. The model studied in this case, can quantify the influence due to the weight of the tower and the creep of the soil. It can explicate the observation on the clay itself quite well.

\section{ACKNOWLEDGEMENT}

Financial support provided by the National Science and Engineering Council of Canada is gratefully acknowledged.

\section{REFERENCES}

1) AGI (1991): The Leaning Tower of Pisa: Present situation. Deformation of soil and displacements of structures, 5th ECSMFE, Florence, Italy, 4, 1437-1445.

2) Bai, J. (1998): Creep analysis of the Leaning Tower of Pisa, Ph.D. Thesis, University of Alberta, Edmonton.

3) Bai, J., Chan, D. and Morgenstern, N. (2008): Numerical analysis of time-dependent behaviour for the Leaning Tower of Pisa, Soils and Foundations, 48(2), 207-220.

4) Bishop, A. E. and Lovenbury, H. T. (1969): Creep characteristics of two undisturbed clays, Proc. ICSMFE, 1, 29-37. 
5) Borja, R. I. and Kavazanjian, E. Jr. (1985): A constitutive model for the stress-strain-time behaviour of 'wet' clays, Geotechnique, 35(3), 283-298.

6) Borja, R. I., Hsieh, H. S. and Kavazanjian, E. Jr. (1990): Doubleyield-surface model, II: Implementation and verification, $A S C E$ Journal of the Geotechnical Engineering Division, 116 (GT9), 1402-1421.

7) Brandes, H. G., Silva, A. J., Sadd, M. H. and Veyera, G. E. (1994): Stress-strain-time modeling of submarine slopes, Proc. 8th Int. Conf. on Computer Methods and Advances in Geomechanics, 3, 2435-2445.

8) Burland, J. B. and Potts, D. M. (1995): Development and application of a numerical model for the Leaning Tower of Pisa, Special Lecture, International Symposium on Pre-Failure Deformation Characteristics of Geo-Materials, IS-Hokkaido, 715-738.

9) Calabresi, G., Rampello, S. and Callisto, L. (1992): Geotechnical characterisation of the tower's subsoil within the framework of the critical state theory, Universita'di Roma, Dipartimento di Ingegneria Strutturale.

10) Chan, D. H. and Morgenstern, N. R. (1992): User Manual of Program PISA ${ }^{\circledR}$, University of Alberta, Edmonton.

11) Cormeau, I. C. (1975): Numerical stability in quasi-static elasto/visco-plasticity, International Journal for Numerical Methods in Engineering, 9, 109-127.

12) Croce, A., Burghignoli, A., Calabresi, G., Evangelista, A. and Viggiani, C. (1981): The Tower of Pisa and the surrounding square: Recent observations, Proc. 5th ICSMFE, Stockholm, 3, 61-70.

13) Grabe, J. and Gudehus, G. (1992): The Leaning Tower of Pisa: Geotechnical theory and model tests, Soils and Foundations, 32(3), 130-136.

14) Hsieh, H. S., Borja, R. I. and Kavazanjian, E. Jr. (1990): Double- yield-surface model, I: Theory. ASCE Journal of the Geotechnical Engineering Division, 116(GT9), 1381-1401.

15) Jamiolkowski, M., Levi, F. and Lancellotta, R. (1993): Leaning Tower of Pisa-updated information, Third International Conference on Case Histories in Geotechnical Engineering, St. Louis, Missouri, 2, 1319-1330.

16) Lizzi, F. (1990): The consolidation of the Leaning Tower of Pisa and the preservation of the Venice Lagoon, Geotechnical Aspects of Restoration Works, Balkema, Rotterdam, 17-33.

17) Mitchell, J. K. and Soga, K. (1995): Numerical and experimental studies related to the performance and stabilisation of the Tower of Pisa, Report to the Consorzio Progetto Torre di Pisa.

18) Morsy, M. M. (1994): Effective stress modelling of creep behaviour of clay, Ph.D. Thesis, University of Alberta, Edmonton.

19) Morsy, M. M., Morgenstern, N. R. and Chan, D. H. (1995): Simulation of creep deformation in the foundation of Tar Island Dyke, Canadian Geotechnical Journal, 32, 1002-1023.

20) PISA ${ }^{\circledR}$ (2007): Program for Incremental Stress Analysis, www.pisa.ab.ca.

21) Singh, A. and Mitchell, J. K. (1968): Generalised stress-strain-time function for soil, ASCE Journal of Soil Mechanics and Foundation Engineering Division, 94(SM1), 21-46.

22) Taylor, D. W. (1948): Fundamentals of Soil Mechanics, New York, Wiley.

23) Verlag La Torre s.r.1. (1984): Pisa in the Centuries.

24) Wheeler, P. (1995): Work suspended as Pisa delivers surprise, Ground Engineering. Oct., 4.

25) Zienkiewicz, O. C. and Cormeau, I. C. (1974): Visco-plasticity, plasticity and creep in elastic solids-A unified numerical approach, International Journal for Numerical Methods in Engineering, 8, 821-845. 